\title{
Prescribing patterns of nurse practitioners in Canada
}

\author{
Esther Sangster-Gormley RN PhD
}

See also CMAJ Open article www.cmajopen.ca/content/3/3/E299

$\mathrm{A}$ cross Canada, governments are seeking opportunities to strengthen the health care system by increasing access to primary care. One approach policy-makers are undertaking is to increase the role of nurses and nurse practitioners. Nurse practitioners are registered nurses with additional education, usually a master's degree, who may order and interpret diagnostic tests, communicate a diagnosis to patients and prescribe medications. ${ }^{1}$ Their numbers almost doubled to 3655 between 2008 and 2013, and they are registered in all Canadian provinces and territories, with most found in Ontario. ${ }^{2}$ In 2013, Canadians spent $\$ 28.8$ billion on prescription drugs, $15.7 \%$ of which were prescribed for conditions affecting the cardiovascular system. ${ }^{3}$ Some of these medications would have been prescribed by nurse practitioners; therefore, it is timely to consider prescribing by nurse practitioners from a health policy perspective.

In a linked research article in CMAJ Open, Tranmer and colleagues ${ }^{4}$ report on trends and patterns of prescribing by nurse practitioners in Ontario over a 10-year period. Their study is the first to document nurse practitioners' prescribing patterns in Canada and provides a baseline. It shows how the practice of nurse practitioners in Ontario had shifted by 2010 to the provision of primarily chronic care from the initial provision of predominantly acute episodic care. ${ }^{4}$ In 2010, nurse practitioners and family physicians were prescribing similar drugs, most of which were indicated for the treatment of chronic health conditions, such as cardiovascular disease. Tranmer and colleagues found that statins were the drug class most frequently prescribed by nurse practitioners. ${ }^{4}$ Statins are the third most commonly prescribed drug class in Canada. ${ }^{3}$ Historically, physicians have been the only health professionals with authority to prescribe. Consequently, comparing a cohort of nurse practitioners and family physicians strengthens the evidence indicating that these two groups have similar prescribing patterns in primary care.

Between 2000 and 2010, nurse practitioners in Ontario had limited authority to prescribe and were regulated to prescribe a pre-approved list of drugs; often their authority was limited to renewing a drug first prescribed by a physician. Since 2011, their prescribing privileges have expanded to more classes of drugs, including controlled drugs and substances. ${ }^{4}$ The next steps will be to determine whether the treatments prescribed are appropriate and effective.

Most of the evidence on prescribing patterns of nurse practitioners comes from the United States, where nurse practitioners have been prescribing autonomously since the 1990s. Researchers have found that nurse practitioners in the US prescribe appropriately and have prescribing patterns similar to those of physicians. ${ }^{5,6}$ Using data from the National Ambulatory Medical Care Survey, Hooker and Cipher ${ }^{5}$ analyzed 149202 primary care visits over a six-year period in which a prescription was written by a nurse practitioner, a physician assistant or a physician. The therapeutic classes prescribed and the number of prescriptions written per visit were similar between the three groups. Running and $\mathrm{Kipp}^{6}$ conducted chart reviews of 200 prescriptions written by nurse practitioners and 200 written by physicians to compare their prescribing patterns in primary care. Overall, there were only slight differences in prescriptions written between the two providers. Nurse practitioners tended to prescribe more overthe-counter medications and recommend more nonpharmacologic treatments to patients than physicians did, which suggests that nurse practitioners may approach prescribing more cautiously and include more patient teaching. ${ }^{6}$

Evidence shows that patients are satisfied with the care provided by nurse practitioners. Newhouse and colleagues ${ }^{7}$ conducted a systematic

\section{KEY POINTS}

- Nurse practitioners are relatively new additions to the Canadian health care system.

- Evidence suggests that patients are satisfied with the care provided by nurse practitioners.

- The prescribing patterns of nurse practitioners in primary care are similar to those of physicians.

- There appears to be no increased risk of liability associated with adding nurse practitioners to the health care system. 
review of published literature between 1990 and 2008, which included 14 randomized controlled trials and 23 observational studies. When comparing care provided by nurse practitioners and physicians, there was strong evidence supporting equivalent patient satisfaction for both providers. Similarly, patients' perceptions of their health status were similar regardless of whether care was provided by a nurse practitioner or a physician. ${ }^{7}$

In terms of overall safety and liability, Hooker and colleagues ${ }^{8}$ reviewed 17 years of data (19912007) compiled by the US National Practitioner Data Bank to compare malpractice incidence, payment amounts and liability by physicians, nurse practitioners and physician assistants. The data included 324285 entries involving 273693 providers. Of the US\$74 billion paid out for malpractice claims, only $0.007 \%$ was for claims involving nurse practitioners and $0.003 \%$ for claims involving physician assistants. Nurse practitioners were 24.4 times less likely than physicians to require payouts for malpractice. ${ }^{8}$ Based on the accumulated evidence, adding nurse practitioners to the US health care system has been safe and beneficial.

Given that the education and scope of practice of nurse practitioners in Canada is similar to that in the US, similar findings would be expected in Canada. With a 40-year history of research into the safety and effectiveness of care provided by nurse practitioners, ${ }^{9}$ researchers might consider studying the contributions nurse practitioner-physician teams make to the delivery of primary care in Canada, as well as patient outcomes directly associated with care provided by nurse practitioners. ${ }^{10}$

\section{References}

1. The nurse practitioner [position statement]. Ottawa: Canadian Nurses Association; 2009. Available: http://cna-aiic.ca/ /media/ cna/page-content/pdf-en/ps_nurse_practitioner_e.pdf (accessed 2015 Aug. 4).

2. Regulated nurses, 2013 report. Ottawa: Canadian Institute for Health Information; 2014. Available: https://secure.cihi.ca/free products/Nursing-Workforce-2013_EN.pdf (accessed 2015 Aug. 4).

3. Prescribed drug spending in Canada, 2013: a focus on public drug programs. Ottawa: Canadian Institute for Health Information; 2015. Available: https://secure.cihi.ca/estore/productFamily.htm ?locale=en\&pf=PFC2896\&lang=en (accessed 2015 Aug. 4).

4. Tranmer JE, Colley L, Edge DS, et al. Trends in nurse practitioners' prescribing to older adults in Ontario, 2000-2010: a retrospective cohort study. CMAJ Open 2015;3:E299-304.

5. Hooker RS, Cipher DJ. Physician assistant and nurse practitioner prescribing: 1997-2002. J Rural Health 2005;21:355-60.

6. Running A, Kipp C. Prescriptive patterns of nurse practitioners and physicians. J Am Acad Nurse Pract 2006;18:228-33.

7. Newhouse RP, Stanik-Hutt J, Whtie KM, et al. Advanced practice nurse outcomes 1990-2008: a systematic review. Nurs Econ 2011;29:230-51.

8. Hooker RS, Nicholson JG, Tuan L. Does the employment of physician assistants and nurse practitioners increase liability? J Med Licensure Discipline 2009;95:6-16.

9. Bauer JC. Nurse practitioners as an underutilized resource for health reform: evidence-based demonstrations of costeffectiveness. J Am Acad Nurse Pract 2010;22:228-31.

10. Sangster-Gormley E, Frisch N, Schreiber R. Articulating new outcomes of nurse practitioner practice. J Am Assoc Nurse Pract 2013;25:653-8.

Affiliation: School of Nursing, University of Victoria, Victoria, $\mathrm{BC}$ 